Research Article : Open Access

\title{
Polarization of Human THP-1 Macrophages: Link between Adenosine Receptors, Inflammation and Lipid Accumulation
}

\author{
Michael J. Littlefield, Isaac Teboul, Iryna Voloshyna and Allison B. Reiss*
}

Winthrop Research Institute and Department of Medicine, Winthrop-University Hospital, NY, USA

*Corresponding author: Allison B. Reiss, Department of Medicine, Winthrop-University Hospital, 222 Station Plaza, North, Suite 502, Mineola, NY 11501, USA, Tel: 516-663-3455; Fax: 516-663-4710; E-mail: AReiss@winthrop.org

\begin{abstract}
Rationale: Macrophages are key players in inflammation and atherosclerosis. They express surface receptors of different subtypes for the endogenous autocoid adenosine. Macrophages within atherosclerotic lesions attain two clear-cut functional phenotypes M1 (pro-inflammatory) and M2 (immunosuppressive). This study examines the relative expression of adenosine receptors and proteins involved in cholesterol transport in THP-1 human macrophages upon differentiation into M1 and M2 subtypes.

Methods: THP-1 human monocytes were cultured in the presence of 100nM PMA. When a differentiated non-polarized phenotype (M0) was achieved, cells were incubated in the presence of $20 \mathrm{ng} /$ $\mathrm{ml}$ interferon- $\mathrm{\gamma}+100 \mathrm{ng} / \mathrm{ml}$ LPS to obtain M1 macrophages or $20 \mathrm{ng} / \mathrm{ml} \mathrm{IL-4}$ to obtain M2 subset. Phenotypes were confirmed via QRT-PCR and by flow cytometry. Expression of cholesterol efflux proteins (ABCA1, ABCG1, SR-B1 and 27 hydroxylase) and scavenger receptors (CD36, SR-A1, LOX1 and CXCL16) was analyzed by QRT-PCR and confirmed by Western blot.

Results: The M1 subset of macrophages display reduced expression of cholesterol efflux proteins: ABCA1, SR-B1 and 27 hydroxylase, as compared to M0 and M2. However, expressions of SR-B1 and 27-hydroxylase $(27 \mathrm{OH})$ are lower in both $\mathrm{M} 1$ and M2 when compared to not polarized M0 subset. Moreover, M2 polarized macrophages display an increased expression of the major scavenger receptors: CD36, SR-A1 and LOX1. This provides an explanation for significantly higher internalization of oxLDL and foam cell formation in M2 versus M1. Our results demonstrate that the M1 phenotype is associated with upregulation of the A2AR and A2BR while the M2 phenotype displays enhanced $A 1$ and $A 3 R$ expression.
\end{abstract}

\section{Keywords}

Adenosine, Inflammation, Atherosclerosis, Cholesterol transport

\section{Abbreviations}

ABC transporters: ATP-Binding Cassette Transporters, CD36: Cluster of Differentiation 36, CXCL16: Chemokine CXC Ligand 16, CXCL10: Chemokine CXCLigand 10, CCL17: Chemokine CC Ligand 17, CCR7: Chemokine CC Receptor 7, LPS: Lipopolysaccharide, GAPDH: Glyceraldehyde-3-Phosphate Dehydrogenase, LDL: Low-Density Lipoprotein, LOX1: Lectin-like Oxidized Low-Density Lipoprotein Receptor, PMA: Phorbol 12-Myristate 13-Acetate,
RCT: Reverse Cholesterol Transport, SR-A1: Scavenger Receptor Class A Type 1, SR-B1: Scavenger Receptor Class B Type 1, $27 \mathrm{OH}-27$-Hydroxylase.

\section{Introduction}

Inflammation is the reaction of the immune system to infection or injury and has been implicated in the pathogeneses of multiple diseases such as arthritis, cancer, and stroke, as well as neurodegenerative and cardiovascular disorders [1-4]. Intrinsically, inflammation is a beneficial event that leads to restoration of tissue structure and physiological functions. The macrophage is an integral part of innate and adaptive immunity and is composed of two subtypes that are either pro-inflammatory or anti-inflammatory [5]. The classically activated or M1 macrophage phenotype produces inflammatory cytokines, like tumor necrosis factor (TNF)- $\alpha$, that trigger acute inflammation. The alternatively activated M2 phenotype is anti-inflammatory and has been found to play an important role in tissue and wound repair [6,7]. Although the usual outcome of the acute inflammatory response is successful resolution and repair of tissue damage, dysfunction may predispose to autoimmunity, chronic inflammation, and accumulating tissue damage [8,9]. Overproduction of M1 pro-inflammatory macrophages has also been linked to the development of atherosclerosis [10,11].

Stress and inflammation cause an interruption in oxygen supply (i.e., hypoxia) and accumulation of extracellular adenosine [12-14]. Adenosine signaling pathways are activated via one of its specific G-coupled protein receptors: A1R, A2AR, A2BR, and A3R. There is growing evidence that the function of the adenosine receptors is crucial in an anti-inflammatory response, reducing ischemiareperfusion injury in multiple organs [15-18]. Previous studies demonstrate that $\mathrm{A} 2 \mathrm{AR}$ and $\mathrm{A} 3 \mathrm{R}$ activation inhibit the nuclear factor (NF) $-\kappa B$ signaling pathway. The NF- $\kappa B$ pathway triggers the transcription of the TNF- $\alpha$ gene $[19,20]$. Hence, A2AR and A3R agonists are proposed as candidates for anti-rheumatic agents due to their ability to reduce expression of TNF- $\alpha[20,21]$.

Anti-inflammatory properties of $\mathrm{A} 2 \mathrm{AR}$ and $\mathrm{A} 2 \mathrm{BR}$ agonists are associated with their anti-atherogenic capabilities, as indicated by

Citation: Littlefield MJ, Teboul I, Voloshyna I, Reiss AB (2014) Polarization of Human THP-1 Macrophages: Link between Adenosine Receptors, Inflammation and Lipid Accumulation. Int J Immunol Immunother. 1:001

Received: October 31, 2014: Accepted: December 05, 2014: Published: December 08, 2014

Copyright: (c) 2014 Littlefield MJ. This is an open-access article distributed under the terms of the Creative Commons Attribution License, which permits unrestricted use, distribution, and reproduction in any medium, provided the original author and source are credited. 
previous studies performed by our group [22,23] and others [24]. The anti-atherogenic effect of activation of $\mathrm{A} 2 \mathrm{AR}$ is attributed to its enhancement of reverse cholesterol transport by upregulating cholesterol 27-hydroxylase and the ATP binding cassette transporter A1 (ABCA1), a transporter that mediates cholesterol efflux to lipidpoor apolipoproteins [25].

This study defines a link between changes in expression of adenosine receptors and cholesterol handling in polarized THP-1 human macrophages. Our results demonstrate that the M1 phenotype is associated with upregulation of the $\mathrm{A} 2 \mathrm{AR}$ and $\mathrm{A} 2 \mathrm{BR}$ while the $\mathrm{M} 2$ phenotype displays enhanced A1 and A3R expression. Accordingly, the M1 phenotype amasses less oxLDL than the M2 phenotype, which corresponds to reduced foam cell formation.

\section{Materials and Methods}

\section{Cells and reagents}

THP-1 monocytes were obtained from the American Type Culture Collection (Rockville, MD). Cell culture media and supplementary reagents were obtained from Invitrogen (Carlsbad, CA).

Phorbol 12-myristate 13-acetate (PMA) and Oil red $\mathrm{O}$ were purchased from Sigma-Aldrich (St. Louis, MO).

The selective A2AR antagonist 4-(2-[7-amino-2-(2-furyl) [1,2,4] triazolo[2,3-a] [1,3,5]triazin-5-ylamino]ethyl)phenol (ZM241385) was purchased from from Abcam Inc. (Cambridge, MA). The selective A2AR antagonist 8-[(E)-2-(3,4-Dimethoxy-phenyl)vinil]-1,3_diethyl-7-methyl-3,7-dihydro-purine-2,6-dione (KW6002) was obtained from Axon Medchem (Groningen, Netherlands).

Trizol reagent was purchased from Invitrogen (Carlsbad, CA). All reagents for reverse transcription-polymerase chain reaction (RTPCR) were purchased from Applied Biosystems (Foster City, CA). SYBR Green Master mix for the quantitative real-time polymerase chain reaction (QRT-PCR) was obtained from Roche Applied Science (Penzberg, Germany). Primers used in amplification reactions were generated by Sigma-Genosys (St. Louis, MO).

\section{Cell culture}

Cell culture media and supplementary reagents were obtained from Invitrogen (Carlsbad, CA). The THP-1 human monocytic leukemia cell line was chosen for the study because it shares many properties with normal human monocytes, including expression of scavenger receptors and cholesterol transport proteins, and is a well-accepted model for atherosclerosis used in our laboratory $[26,27]$ and many others.

THP-1 monocytes (American Type Culture Collection, Manassas, VA) were grown at $37^{\circ} \mathrm{C}$ in a $5 \% \mathrm{CO}_{2}$ atmosphere in RPMI 1640 supplemented with $10 \%$ fetal calf serum (FCS), 50 units $/ \mathrm{ml}$ penicillin, and $50 \mathrm{units} / \mathrm{ml}$ streptomycin. To facilitate differentiation into macrophages, THP-1 monocytes were treated with 100nM PMA for $24 \mathrm{~h}$ at $37^{\circ} \mathrm{C}$. When a differentiated non-polarized phenotype (M0) was achieved, the PMA-containing medium was removed, and replaced with complete RPMI 1640 supplemented with 10\% FCS for another 24 hours.

In order to generate polarized phenotypes, cells were then cultured for 48 hours in the presence of $20 \mathrm{ng} / \mathrm{ml}$ interferon- $\gamma$ and $100 \mathrm{ng} / \mathrm{ml}$ LPS to obtain M1 macrophages [28,29] or $20 \mathrm{ng} / \mathrm{ml}$ IL-4 to obtain M2 macrophages [30]. Phenotypes were confirmed via QRTPCR analysis of gene expressions in commonly used cell surface markers IL-12, CCR7, and CXCL10 for M1 and CD163, mannose receptor, and CCL17 for M2 [31,32] (Table 1).

Phenotypical changes in macrophages were verified by flow cytometry using a BD Accuri C6 flow cytometer (BD Biosciences, Franklin Lakes, NJ). Both M1 and M2 phenotypes were stained with a PE conjugated $\mathrm{mAb}$ to $\mathrm{CD} 163$, a FITC conjugated $\mathrm{mAb}$ to CD68, an APC-conjugated $\mathrm{mAb}$ to $\mathrm{CD} 11 \mathrm{~b}$, and a PE/Cy7 conjugated $\mathrm{mAb}$ to $\mathrm{CD} 14$, as well as isotype matched control mAbs, for 30 minutes at room temperature according to the manufacturer's instructions (Abcam, Cambridge, MA) [31-33].
Table 1: Macrophage phenotype markers used for QRT-PCR.

\begin{tabular}{|c|l|}
\hline Gene & \multicolumn{1}{c|}{ Primer } \\
\hline IL-12 & $\begin{array}{l}\text { F 5'-AAAGGACATCTGCGAGGAAAGTTC-3' } \\
\text { R 5'-CGAGGTGAGGTGCGTTTATGC-3' }\end{array}$ \\
\hline CCR7 & F 5'-TGGTGGTGGCTCTCCTTGTC-3' \\
& R 5'-TGTGGTGTTGTCTCCGATGTAATC-3' \\
\hline CXCL10 & F 5'-GAAAGCAGTTAGCAAGGAAAGGTC-3' \\
& R 5'-ATGTAGGGAAGTGATGGGAGAGG-3' \\
\hline CD163 & F 5'-GTCGCTCATCCCGTCAGTCATC-3' \\
& R 5'-GCCGCTGTCTCTGTCTTCGC-3' \\
\hline Mannose Receptor & F 5'-ACCTCACAAGTATCCACACCATC-3' \\
& R 5'-CTTTCATCACCACACAATCCTC-3' \\
\hline CCL17 & F 5'-CGGGACTACCTGGGACCTC-3' \\
& R 5'-CCTCACTGTGGCTCTTCTTCG-3' \\
\hline
\end{tabular}

Table 2: The list of specific primers used for QRT-PCR.

\begin{tabular}{|c|c|}
\hline Gene & Primer \\
\hline ABCA1 & $\begin{array}{l}\text { F 5'-GAAGTACATCAGAACATGGGC-3' } \\
\text { R 5'-GATCAAAGCCATGGCTGTAG-3' }\end{array}$ \\
\hline ABCG1 & $\begin{array}{l}\text { F 5'-CAGGAAGATTAGACACTGTGG-3' } \\
\text { R 5'-GAAAGGGGAATGGAGAGAAG-3' }\end{array}$ \\
\hline 27-hydroxylase & $\begin{array}{l}\text { F 5'-AAGCGATACCTGGATGGTTG-3' } \\
\text { R 5'-TGTTGGATGTCGTGTCCACT-3' }\end{array}$ \\
\hline CD36 & $\begin{array}{l}\text { F 5'-GAGAACTGTTATGGGGCTAT-3' } \\
\text { R 5'-TTCAACTGGAGAG-GCAAAGG-3' }\end{array}$ \\
\hline LOX-1 & $\begin{array}{l}\text { F 5'-TTACTCTCCATGGTGGTGCC-3' } \\
\text { R 5'-AGCTTCTTCTGCTTGTTGCC-3' }\end{array}$ \\
\hline ScR-A1 & $\begin{array}{l}\text { F 5'-CTCGTGTTTGCAGTTCTCA-3' } \\
\text { R 5'-CCATGTTGCTCATGTGTTCC-3' }\end{array}$ \\
\hline CXCL16 & $\begin{array}{l}\text { F 5'-ACTACACGACGTTCCAGCTCC-3' } \\
\text { R 5'-CTTTGTCCGAGGACAGTGATC-3' }\end{array}$ \\
\hline GAPDH & $\begin{array}{l}\text { F 5'- ACCATCATCCCTGCCTCTAC-3' } \\
\text { R 5'-CCTGTTGCTGTAGCCAAAT-3' }\end{array}$ \\
\hline A1R & $\begin{array}{l}\text { F 5'-GCCACAGACCTACTTCCA-3' } \\
\text { R 5'-CCTTCTCGAACTCGCACTTG-3' }\end{array}$ \\
\hline A2aR & $\begin{array}{l}\text { F 5'-CGAATTCAACCTGCAGAACGTCACC-3 } \\
\text { R 5'-TCGAATTCGCGGTCAATGGCGATG-3' }\end{array}$ \\
\hline $\mathrm{A} 2 \mathrm{bR}$ & $\begin{array}{l}\text { F 5'-CAGACGCCCACCAACTACTT-3' } \\
\text { R 5'-GCCACCAGGAAAATCTTAATG-3' }\end{array}$ \\
\hline$A 3 R$ & $\begin{array}{l}\text { F 5'-ACCACTCACAGAAGAATATG-3' } \\
\text { R 5'--ACTTAGCCGTCTTGAACTCC3' }\end{array}$ \\
\hline
\end{tabular}

\section{RNA extraction and real-time PCR}

Immediately after the incubation period, total RNA was isolated with Trizol (Carlsbad, CA) reagent $\left(1 \mathrm{ml} / 10^{6}\right.$ cells). The quantity of total RNA from each condition was measured by absorption at $260 \mathrm{~nm}$ and $280 \mathrm{~nm}$ wavelengths by ultraviolet spectrophotometry (Hitachi U2010 spectrophotometer).

ABCA1, ABCG1, 27-hydroxylase, SR-B1, PPAR gamma, LXR alpha, LOX1, SR-A1, CXCL16, CD36, A1R, A2aR, and A3R mRNA were quantified by real-time PCR. The cDNA was copied from $1 \mu \mathrm{g}$ of total RNA using Moloney murine leukemia virus reverse transcriptase primed with oligo dT. Equal amounts of cDNA were taken from each RT reaction mixture for PCR amplification using specific primers (Table 2). QRT-PCR analysis was performed using the SYBR Green Reagent Kit according to the manufacturer's instructions on the Roche Light Cycler 480 (Roche Applied Science, Penzburg, Germany). Each reaction was done in triplicate. The amount of PCR products were estimated using Roche Applied Science software, provided by the manufacturer. Fluorescence emission spectra were monitored and analyzed. PCR products were measured by the threshold cycles $\left(\mathrm{C}_{\mathrm{T}}\right)$, at which specific fluorescence becomes detectable. The $\mathrm{C}_{\mathrm{T}}$ value for each gene was normalized to that of glyceraldehydes-3-phosphate dehydrogenase (GAPDH), and the relative expression level was calculated as the mean value of the untreated THP-1 as 1 . Nontemplate controls were included for each primer pair to check for significant levels of any contaminants. A melting-curve analysis was performed to assess the specificity of the amplified PCR products.

\section{Protein extraction and western blot analysis}

Cellular extracts were prepared with Lysis Kit - RIPA Buffer (ProteinSimple, Santa Clara, CA). The immunoreactive proteins were 
A

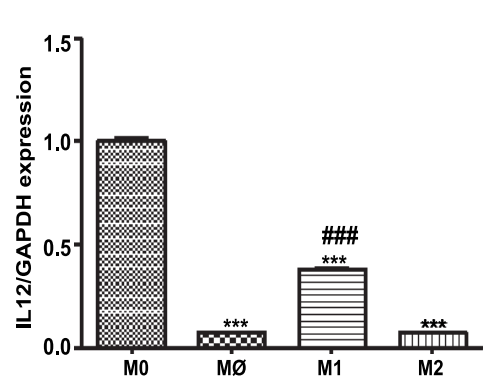

B
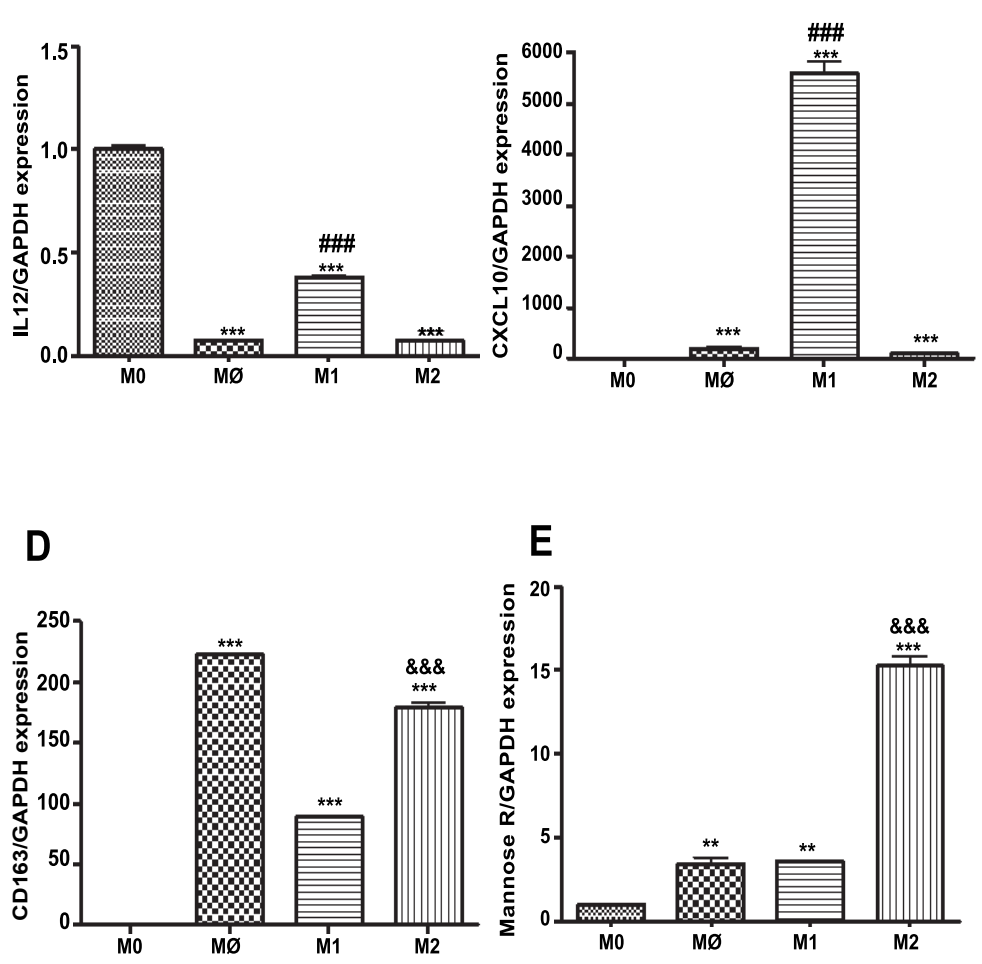

$\mathrm{E}$

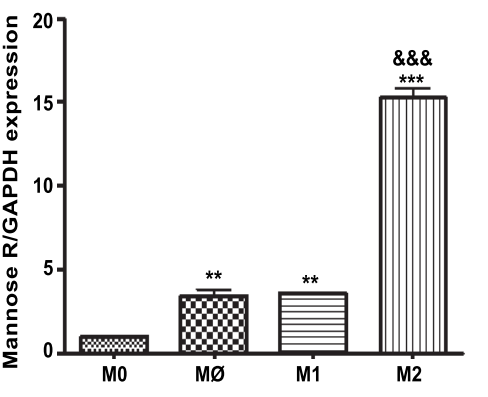

C

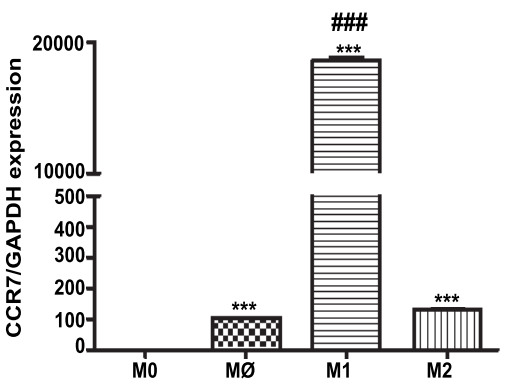

$\mathbf{F}$

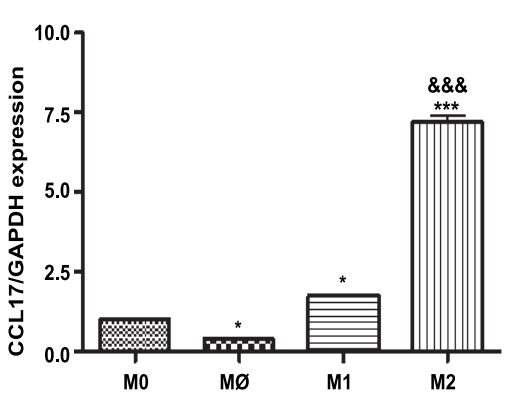

Figure 1: Surface marker expression on THP-1 monocytes, M0 and on M1 and M2 macrophage subsets

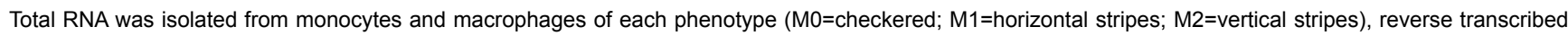
and amplified by PCR with GAPDH message as an internal standard. Gene expression levels were graphed as fold difference in mRNA expression versus monocytes set as 1.0. The data represent the mean \pm SEM of 3 independent experiments. M1 markers: (A) IL-12 expression (B) CXCL10 expression (C) CCR7 expression; M2 markers (D) CD163 expression (E) Mannose Receptor (F) CCL17 expression.

$\left.{ }^{(* *}\right) \mathrm{P}<0.01 ;\left(^{* * *}\right) \mathrm{P}<0.001$ vs. monocytes; (\#\#\#) $\mathrm{P}<0.001$ vs. M2 macrophages; (\&\&\&) $\mathrm{P}<0.001$ vs. M1 macrophages.

detected using Wes Assay kit (ProteinSimple, Santa Clara, CA).

Rabbit anti-human ABCA1 (sc-20794) (Santa Cruz, CA) and rabbit anti-human ABCG1 (ab-36969) (Abcam Inc., Cambrige, MA) were used as primary antibodies for detection of ABCA1 and ABCG1, respectively. Rabbit anti-human LOX1 (ab60178), CD36 (ab64014), SR-A1 (ab36625), CXCL16 (ab101404) were purchased from Abcam Inc. (Cambrige, MA). As a loading control, GAPDH was detected using rabbit anti-human GAPDH antibody (ab9485).

Quantization of detected proteins and image preparation were performed with Compass Software (ProteinSimple, Santa Clara, CA).

\section{Evaluation of foam cell formation by DiI-oxLDL internalization assay}

For the foam cell formation assay, cells were washed in distilled water and stained with $0.2 \%$ Oil Red O (Sigma, St. Louis, MO) for 30 min. After the PBS wash, cell nuclei were stained with hematoxylin (Sigma, St. Louis, MO) for $5 \mathrm{~min}$. After a final wash with PBS, coverslips were mounted on slides using Permount solution (Sigma, St. Louis, MO). Foam cells, recognized as red-stained cells, were visualized via light microscopy (Axiovert 25; Carl Zeiss, Gottingen, Germany) with 40x magnification and photographed using a DC 290 Zoom digital camera (Eastman Kodak, Rochester, NY). The number of foam cells formed in each condition was calculated in triplicate manually and presented as percentage of total cells.

Cells were incubated with $5 \mu \mathrm{g} / \mathrm{ml} 1,1^{\prime}$-dioctadecyl-3,3,3',3'tetramethylin docarbocyaninet (DiI)-oxLDL (Intracel, Frederick, $\mathrm{MD}$ ) for $4 \mathrm{~h}$. Slides were prepared using Vectashield mounting medium containing DAPI stain (Vector Laboratories, Inc., Burlingame, CA). After incubation, accumulation of DiI-oxLDL in cells was determined by fluorescent intensity with a Nikon A1 microscopy unit with 40X magnification and photographed with a DS-Ril digital camera. Fluorescent intensity was quantified from at least 3 random fields (1024x1024 pixels) per slide, from 3 slides per experimental condition and graphed.

\section{Data analysis}

Statistical analysis was performed using Graphpad Prism, version 5.01 (GraphPad Software, San Diego, CA). All data were analyzed by one way ANOVA with a Bonferroni post hoc test to evaluate the statistical significance of intergroup differences in all the tested variables. P values $<0.05$ were considered statistically significant.

\section{Results}

Comparison of surface marker gene expression on THP-1 monocytes and M0, M1 and M2 macrophage subsets

M1 macrophages express IL-12, CCR7, and CXCL10 at significantly higher levels than M2 macrophages $(\mathrm{P}<0.001, \mathrm{n}=3)$ (Figure 1A-C). M2 macrophages express CD163, mannose receptor, and CCL17 at significantly higher levels than M1 macrophages $(\mathrm{P}<0.001, \mathrm{n}=3)$ (Figure 1D-F).

Phenotypes were confirmed via flow cytometric analysis of standardized cell surface markers. Mean fluorescent intensities were analyzed to confirm M1:M2 polarization.

Expression of cholesterol efflux proteins: ABCA1, ABCG1, SR-B1 and 27 hydroxylase in different subsets of macrophages

M1 polarized macrophages display reduced expression of the major cholesterol efflux proteins at levels that significantly differ from the expression profile in M2 polarized macrophages (Figure 2). Thus, 
A

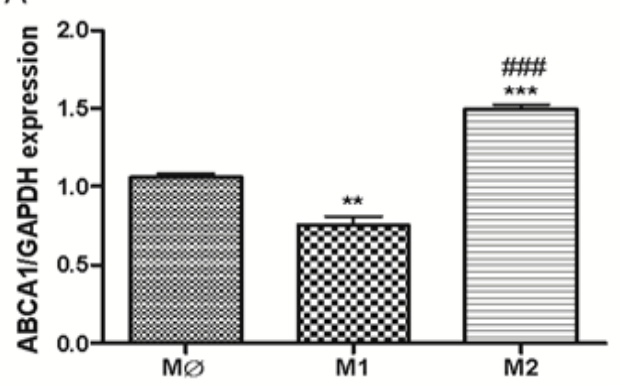

C

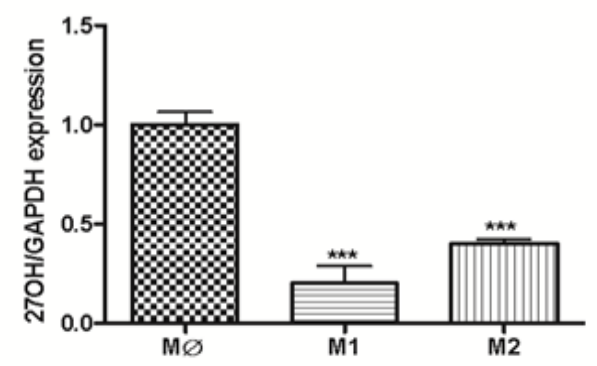

B

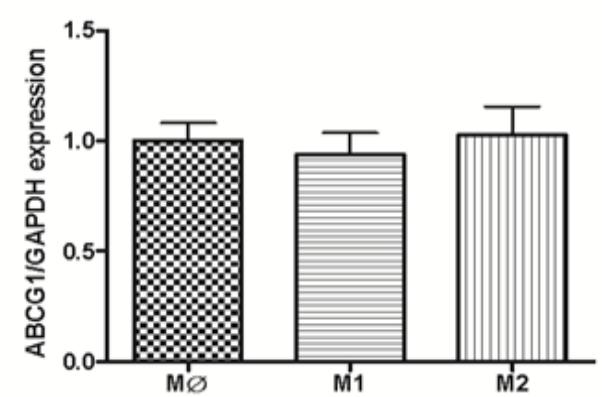

D

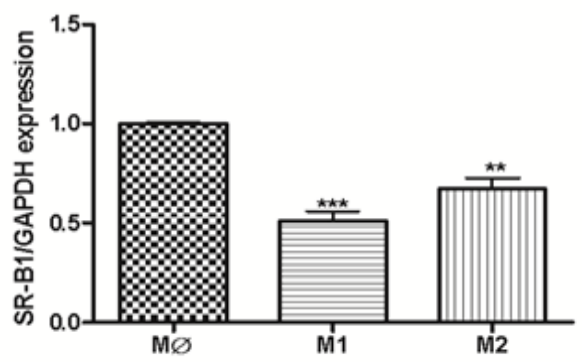

E

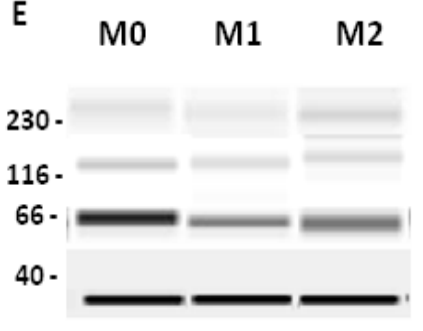

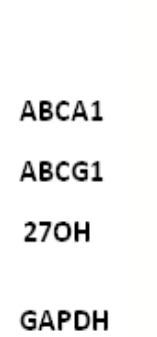

布

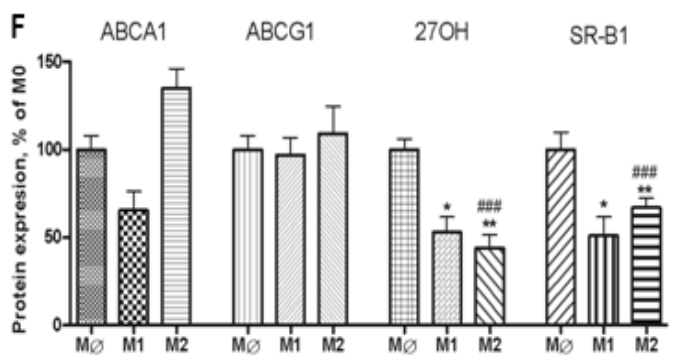

Figure 2: Expression of cholesterol efflux proteins: ABCA1, ABCG1, SR-B1 and 27-hydroxylase (27-OH) in different subsets of THP-1 macrophages.

Gene expression was evaluated in each subset of macrophages (M0 - naïve differentiated with PMA, M1 - IFN/LPS stimulated, and M2 - IL4 stimulated) using equal amounts of cDNA. mRNA levels were graphed as fold difference in mRNA expression versus $M 0$ macrophages set as 1.0. The data represent the mean \pm SEM of 3 independent experiments. (A) ABCA1 expression (B) ABCG1 expression (C) 27OH expression and (D) SR-B1 expression (E) Western Blot for ABCA1, $A B C G 1270 H$, and GAPDH protein expression (F) Relative protein expression levels of ABCA1, ABCG1 27OH, and SR-B1 in M0, M1, and M2 macrophages.

$\left(^{*}\right) \mathrm{P}<0.01 ;\left(^{* *}\right) \mathrm{P}<0.01 ;\left(^{* *}\right) \mathrm{P}<0.001$ vs. M0 macrophages; (\#\#) $\mathrm{P}<0.001$ vs. M1 macrophages.

level of ABCA1, SR-B1 and 27 hydroxylase $(27 \mathrm{OH})$ were $0.54 \pm 0.052$, $0.22 \pm 0.04$ and $0.15 \pm 0.05$ lower than non-polarized M0 macrophages $(\mathrm{P}<0.001, \mathrm{n}=3)$. The level of ABCG1 was not significantly different $(0.90 \pm 0.06)$ upon activation of M1 phenotype compared to M0 and M2 (1.17 \pm 0.016$)$ (Figure 2B). In contrast, M2 macrophages exhibit upregulation in the expression of ABCA1 $(1.49 \pm 0.003)(\mathrm{P}<0.001$, $\mathrm{n}=3$ ) (Figure 2A). Even though mRNA levels of SR-B1 and $27 \mathrm{OH}$ were significantly higher in M2 polarized macrophages versus M1, their levels were reduced as compared to $\mathrm{M} 0$ macrophages (Figure $2 C, D): 0.54 \pm 0.013$ and $0.38 \pm 0.015$, respectively $(\mathrm{P}<0.001, \mathrm{n}=3)$ . Gene expression analysis was confirmed by Western blot (Figure 2E, F).

\section{Expression of Scavenger Receptors: CD36, SR-A1, LOX1 and CXCL16 in Different Subsets of Macrophages}

M1 differentiated macrophages express reduced levels of scavenger receptors: CD36, SR-A1 and LOX1 compared to M2 macrophages (Figure 3). Levels of CD36 and LOX1 were significantly lower: $0.84 \pm$ 0.009 and $0.54 \pm 0.004$, respectively, compared to M0 non-polarized macrophages. In contrast, expression of CXCL16 was 10 fold higher compared to M0 and M2 macrophages $(\mathrm{P}<0.001, \mathrm{n}=3$ ) (Figure $3 \mathrm{D}$ ). $\mathrm{M} 2$ polarized macrophages express 2 fold higher levels of CD36 and SR-A1 $(\mathrm{P}<0.011, \mathrm{n}=3)$ and 4 fold higher LOX1 $(\mathrm{P}<0.011, \mathrm{n}=3)$ (Figure $3 \mathrm{~A}-\mathrm{C})$. The level of CXCL16 was not affected by polarization to M2 phenotype (Figure 3D). Gene expression analysis was confirmed by Western blot (Figure 3E,F).

\section{DiI-oxLDL uptake and foam cell formation in different subsets of macrophages}

In our study, M1 polarized macrophages uptake 1.5 times less DiIoxLDL than M2 differentiated subset $(\mathrm{P}<0.001, \mathrm{n}=3)$, as presented on microphotograph $(\mathrm{x} 40 \mathrm{x})$ (Figure $4 \mathrm{~A})$. Fluorescent intensity was quantified from at least 3 random fields (1024x1024 pixels) per slide, from 3 slides per experimental condition and graphed (Figure 4B). Lower lipid accumulation correlated with decrease in the foam cell formation in M1 versus M2 macrophages (Figure 4A). Consequently, M2 macrophages formed $25.5 \pm 5.4 \%(P<0.001, n=5)$ more foam cells as compared to M1 subset (Figure 4C). Number of foam cells formed in each condition was calculated in triplicate manually and presented as percentage of total cells.

\section{Expression of adenosine receptors on different subsets of human THP-1 macrophages}

Upon polarization, M1 macrophages express 2.5 fold and 3 fold increased $A 2 A R$ and $A 2 B R$, respectively $(\mathrm{P}<0.011, \mathrm{n}=3)$ and a reduced amount of A3R $(\mathrm{P}<0.001, \mathrm{n}=3)$ (Figure $5 \mathrm{~B}-\mathrm{D})$ compared to M0 and M2 subsets. In contrast, M2 macrophages display reduced level of $\operatorname{A2AR}(0.53 \pm 0.022 ; \mathrm{P}<0.001, \mathrm{n}=3)$ and no significant difference in 

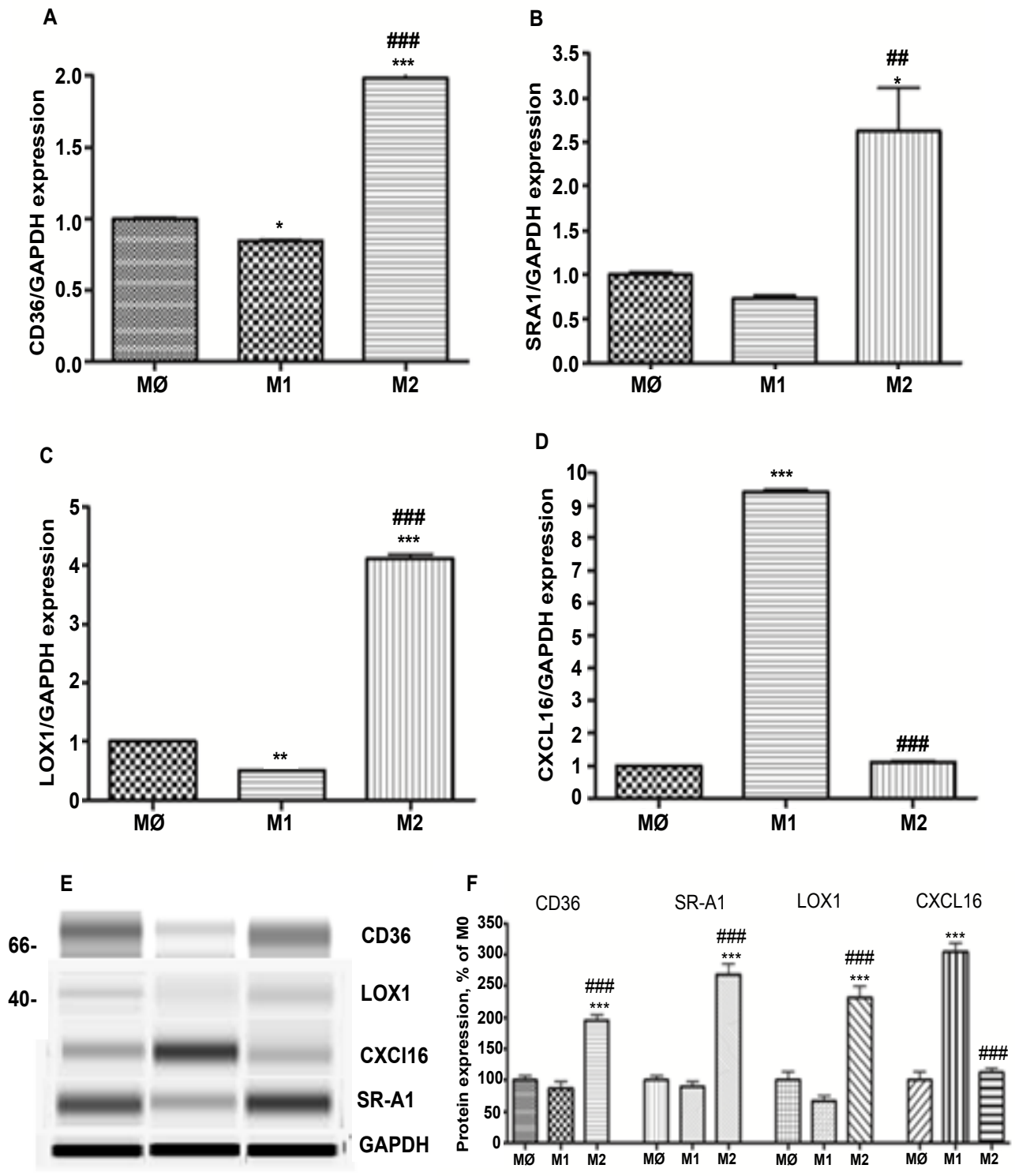

Figure 3: Expression of scavenger receptors: CD36, SR-A1, LOX1 and CXCL16 in different subsets of THP-1 macrophages.

Gene expression was evaluated in each subset of macrophages (M0 - naïve differentiated with PMA, M1 - IFN/LPS stimulated, and M2 - IL4 stimulated) using equal amounts of cDNA. mRNA levels were graphed as fold difference in mRNA expression versus M0 macrophages set as 1.0 . The data represent the mean \pm SEM of 3 independent experiments. (A) CD36 expression (B) SRA1 expression (C) LOX1 expression (D) CXCL16 expression (E) Western Blot for CD36, SRA1, LOX1, CXCL16, and GAPDH protein expression (F) Relative protein expression levels of CD36, SRA1, LOX1, and CXCL16 in M0, M1, and M2 macrophages.

$\left({ }^{*}\right) \mathrm{P}<0.01 ;\left(^{* *}\right) \mathrm{P}<0.01 ;\left(^{* *}\right) \mathrm{P}<0.001$ vs. M0 macrophages; (\#\#) $\mathrm{P}<0.001$ vs. M1 macrophages.

level of A2BR versus M0 macrophages (Figure 5B, Figure 5C). M2 polarized macrophages express 1.5 fold increased $\mathrm{A} 1 \mathrm{R}(\mathrm{P}<0.001, \mathrm{n}=3)$ and 2.2 fold higher $A 3 R(P<0.001, n=3)$ (Figure $5 A, D)$ compared to $\mathrm{M} 0$ and M1 macrophages.

\section{Discussion}

Macrophages promote atherogenesis by internalizing modified lipoproteins that have penetrated the vessel wall to form cholesterolloaded foam cells. The phenotypic switch in macrophages present in atherosclerotic lesions influences disease development and progression [34,35]. Multiple studies have attempted to solve the M1/M2 macrophage polarization paradigm. It is generally accepted that the pro-inflammatory population is pro-atherogenic while the anti-inflammatory subset is atheroprotective [36,37]. However, M1 and M2 macrophages both contribute during diverse stages of human plaque development and localize in distinct morphological points within atherosclerotic lesions. Further, the clearcut difference between M1 and M2 macrophages in vitro is probably not the natural circumstance. Degree of differentiation toward one state or the other probably varies along a spectrum. Thus, evaluation of molecular and biochemical changes upon their differentiation is valuable to our understanding of atheroma progression.

In this study we demonstrate that the M1 phenotype expresses low levels of the proteins involved in cholesterol efflux - ABCA1 and SR-B1 as compared to M2 macrophages. These results are in accord with previous reports by Waldo et al, (2008) and Bouhlel et al, (2007) $[34,38]$. We did not observed changes in the expression of ABCG1 in M1 and M2 subsets, compared to [34], and down regulation of 27-hydroxylase, a protein that provides a pathway for elimination of intracellular cholesterol [39], in both subsets compared to the M0 phenotype. These findings authenticate pro-atherogenic properties in the M1 subset of macrophages. However, expression of SR-B1 and 27-hydroxylase are lower in both M1 and M2 when compared to undifferentiated M0 macrophages (Figure 2). Moreover, M2 polarized macrophages display an increased expression of the major scavenger receptors responsible for modified lipid uptake: CD36, SRA1 and LOX1. This supports the current model for increased lipid uptake in M2 macrophages as reported in Canton et al, (2013) [40]. In 
A
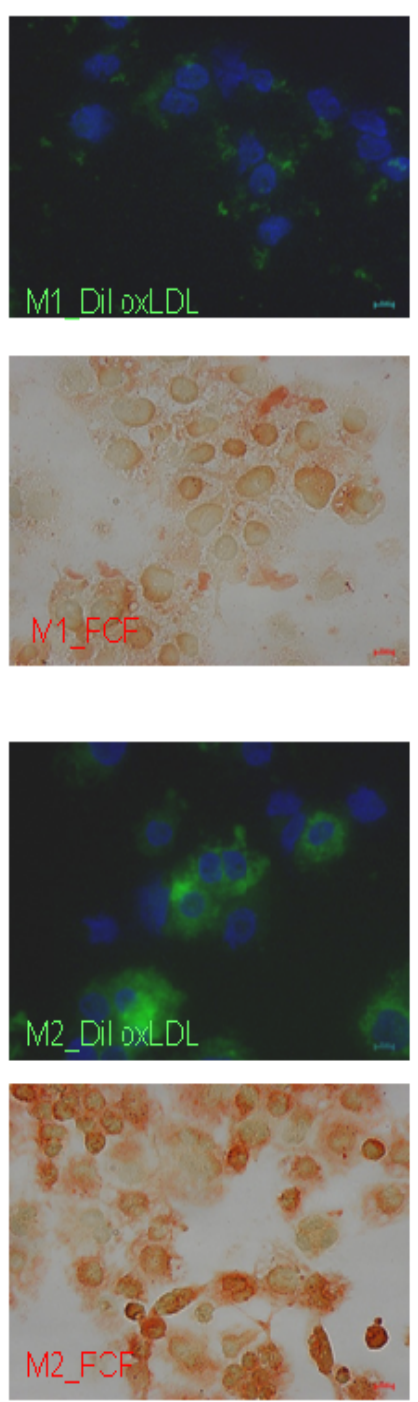

B

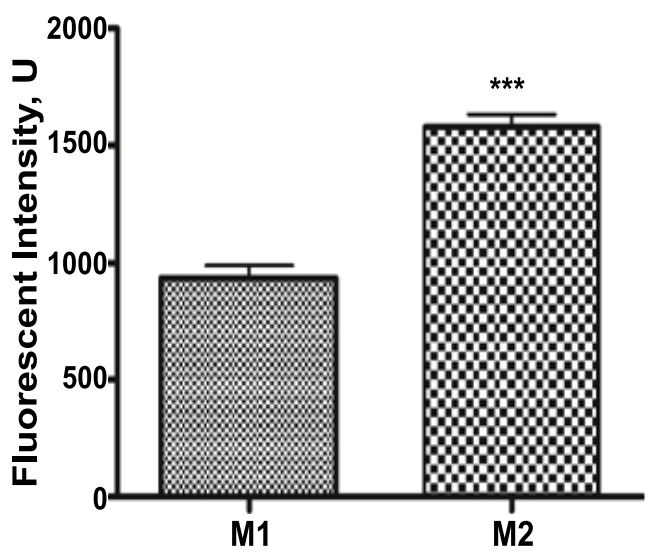

C

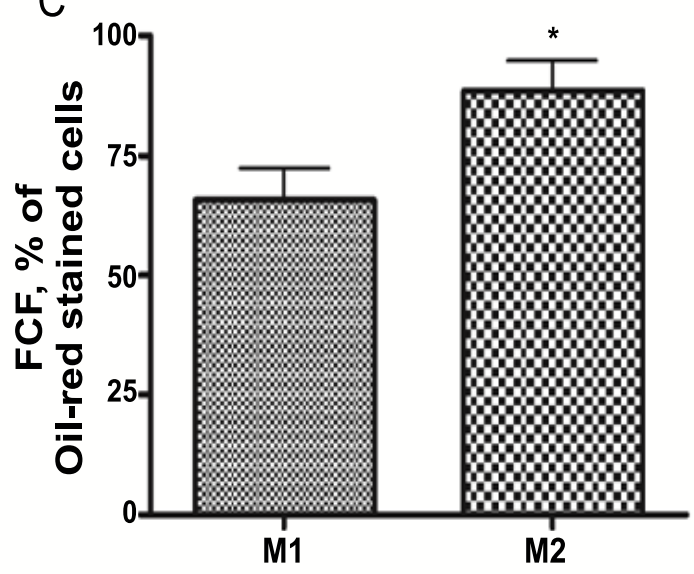

Figure 4: Internalization of Dil-oxLDL and foam cell formation in M1 and M2 THP-1 macrophages.

Cells were photographed with a DS-Ri1 digital cameras (A) Integrated Dil-oxLDL are presented in green, DAPI nuclear staining - in blue and foam cells were recognized by Oil-red-O staining. oxLDL internalization was measured as fluorescent intensity of integrated Dil-oxLDL and graphed (B) Foam cell formation (FCF) was calculated as a percentage of oil-red-O stained cells (C) All results are expressed as means \pm SEM of three independent experiments.

$\left(^{*}\right) \mathrm{P}<0.01 ;\left(^{* *}\right) \mathrm{P}<0.001$ for M1 vs. M2 macrophages.

combination with the decreased level of cholesterol efflux proteins, this provides an explanation for observed difference in the internalization of oxLDL: significantly higher in M2 versus M1 (Figure 4). Lipid accumulation, in turn, leads to elevated foam cell production [40], observed in the M2 population in our study. Interestingly, for the M1 set of macrophages, expression of only one scavenger receptor was increased - chemokine CXC ligand 16 (CXCL16) - a novel scavenger receptor, involved in oxLDL uptake [41].

Despite documented differences in behavior of human and murine macrophages, a preponderance of our data regarding macrophage polarization originates in murine studies, while information on human macrophages remains sparse [42]. Further, the importance of adenosine receptors in atherosclerosis progression has been explored in murine models and not evaluated properly in humans. Thus, in the present study, conducted in a human cell line, we observed that M1 polarization is associated with upregulation of the A2AR and A2BR while $\mathrm{M} 2$ polarization enhances $\mathrm{A} 1$ and $\mathrm{A} 3 \mathrm{R}$ expression.

While studies have shown possible beneficial effects of A2AR activation on the survival rate in septic murine models, recent evidence has shown that pharmacologic blockade of the A2AR using selective antagonists such as ZM-241385 decreases mouse mortality under septic conditions [17]. As these data occur in septic/inflammatory models where the distribution of polarized macrophages is shifted toward the M1 phenotype, future studies are indicated to further elucidate adenosine receptor activity in both M1 and M2 macrophages. Determining the effects of A2AR inhibition on macrophage polarization will also add to our understanding of the complicated physiology of adenosine action.

The clinical relevance of the present work is highlighted by the ongoing Cardiovascular Inflammation Reduction Trial (CIRT), an $\mathrm{NIH}$-sponsored randomized, double blind, placebo-controlled clinical trial designed to determine whether low dose methotrexate will reduce recurrent cardiovascular events in 7,000 stable patients who are postmyocardial infarction or have documented coronary artery disease with type 2 diabetes or metabolic syndrome [43]. Atheroprotective effects of methotrexate are mediated, at least in part, through elevation of adenosine levels and thus the impact of methotrexate on the cardiovascular health of these patients may be dependent on macrophage phenotype in their arterial plaques [44]. Other potential approaches to controlling macrophage cholesterol accumulation may involve dietary supplements such as resveratrol which has low toxicity and may act on cholesterol transport proteins through adenosine or other signaling pathways [45, 46] Given the contrasting properties of pro-inflammatory M1 and antiinflammatory M2 macrophages in homeostasis and disease, considering the balance between these populations has been deemed crucial in 
A

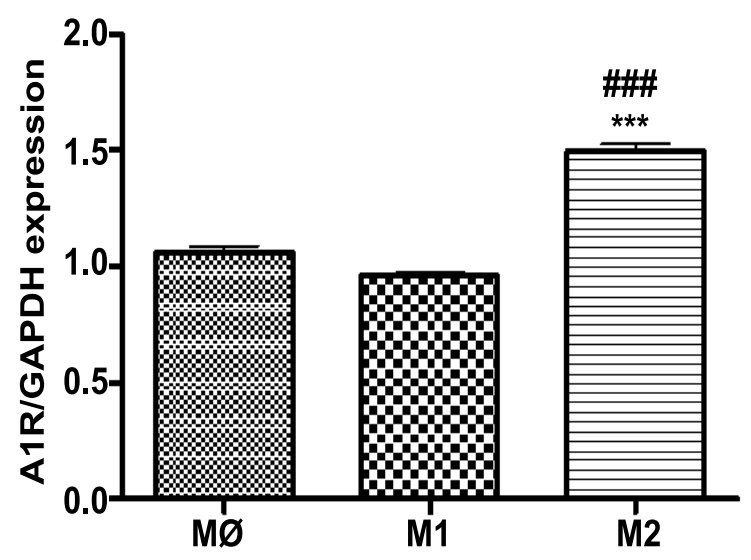

C

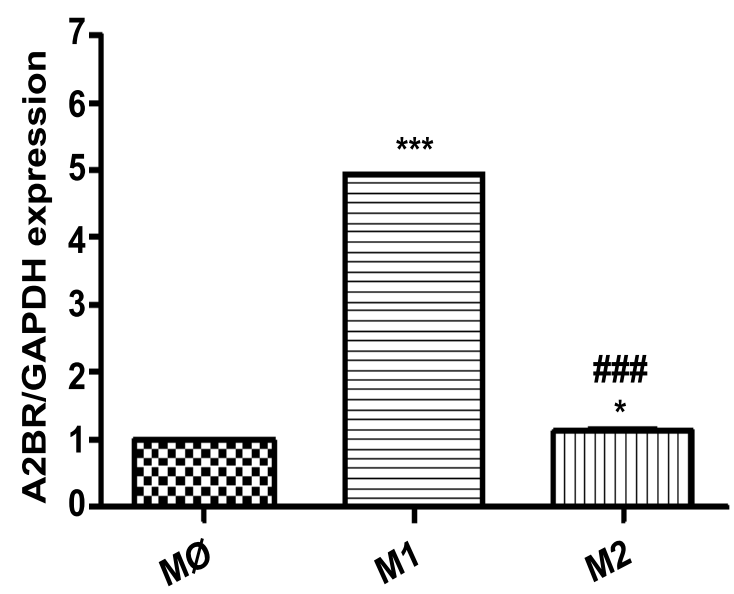

B

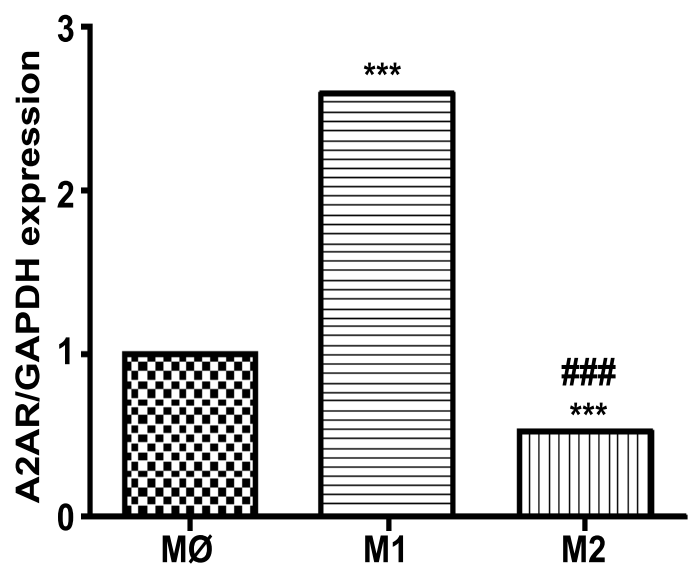

D

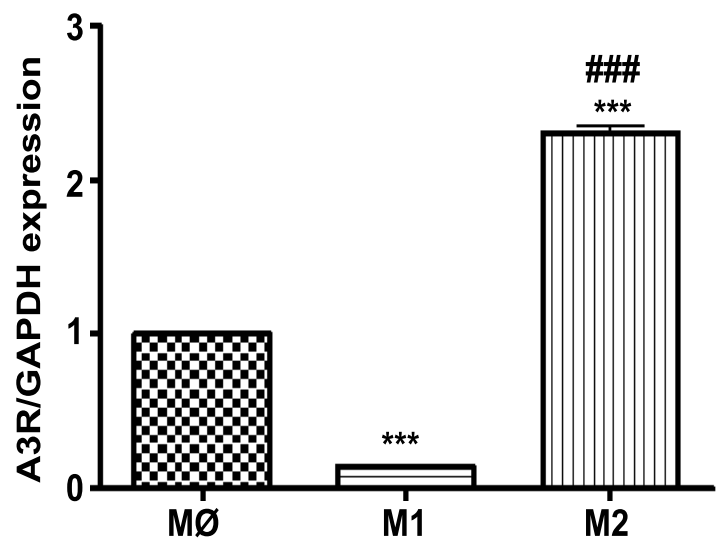

Figure 5: Expression of adenosine receptors: $A 1, A 2 A, A 2 B$ and $A 3$ in THP-1 macrophage subsets.

Gene expression was evaluated in different subsets of macrophages (M0=naïve differentiated with PMA, M1=IFN/LPS stimulated, and M2=IL4 stimulated) using equal amounts of cDNA. mRNA levels were graphed as fold difference in mRNA expression versus M0 macrophages set as 1.0. The data represent the mean \pm SEM of 3 independent experiments. (A) A1R expression (B) A2AR expression (C) A2BR expression (D) A3R expression.

$\left.\left(^{\star *}\right) \mathrm{P}<0.01 ;{ }^{* * *}\right) \mathrm{P}<0.001$ vs. M0 macrophages; (\#\#) $\mathrm{P}<0.001$ vs. M1 macrophages.

developing therapeutic remedies.

\section{Acknowledgements}

This work was supported by R21 AT007032-01A1 from The National Center for Complementary and Alternative Medicine and by the Elizabeth Daniell Research Fund.

\section{References}

1. García-Gómez C, Bianchi M, de la Fuente D, Badimon L, Padró T, et al (2014) Inflammation, lipid metabolism and cardiovascular risk in rheumatoid arthritis: A qualitative relationship? World J Orthop 5: 304-311.

2. Bentzon JF, Otsuka F, Virmani R, Falk E2 (2014) Mechanisms of plaque formation and rupture. Circ Res 114: 1852-1866.

3. Diakos CI, Charles KA2, McMillan DC3, Clarke SJ4 (2014) Cancer-related inflammation and treatment effectiveness. Lancet Oncol 15: e493-503.

4. Urrutia PJ, Mena NP, Núñez MT (2014) The interplay between iron accumulation, mitochondrial dysfunction, and inflammation during the execution step of neurodegenerative disorders. Front Pharmacol 5: 38.

5. Galván-Peña S, O'Neill LA (2014) Metabolic reprograming in macrophage polarization. Front Immunol 5: 420.

6. Liu YC, Zou XB2, Chai YF1, Yao YM3 (2014) Macrophage polarization in inflammatory diseases. Int J Biol Sci 10: 520-529.

7. Xu W, Zhao X, Daha MR, van Kooten C (2013) Reversible differentiation of pro- and anti-inflammatory macrophages. Mol Immunol 53: 179-186.

8. McNelis JC, Olefsky JM2 (2014) Macrophages, immunity, and metabolic disease. Immunity 41: 36-48.

9. Szondy Z, Garabuczi E1, Joós G1, Tsay GJ2, Sarang Z3 (2014) Impaired clearance of apoptotic cells in chronic inflammatory diseases: therapeutic implications. Front Immunol 5: 354.

10. Hoeksema MA, Stöger JL, de Winther MP (2012) Molecular pathways regulating macrophage polarization: implications for atherosclerosis. Curr Atheroscler Rep 14: 254-263.

11. Mantovani A, Garlanda C, Locati M (2009) Macrophage diversity and polarization in atherosclerosis: a question of balance. Arterioscler Thromb Vasc Biol 29: 1419-1423.

12. Fredholm BB (2007) Adenosine, an endogenous distress signal, modulates tissue damage and repair. Cell Death Differ 14: 1315-1323.

13. Ouyang X, Ghani A, Malik A, Wilder T, Colegio OR, et al. (2013) Adenosine is required for sustained inflammasome activation via the $A$ â,,A receptor and

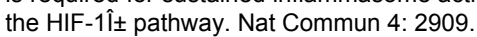

14. Cauwels A, Rogge E, Vandendriessche B, Shiva S, Brouckaert P (2014) Extracellular ATP drives systemic inflammation, tissue damage and mortality. Cell Death Dis 5: e1102.

15. Zhong H, Belardinelli L, Maa T, Feoktistov I, Biaggioni I, et al. (2004) A(2B) adenosine receptors increase cytokine release by bronchial smooth muscle cells. Am J Respir Cell Mol Biol 30: 118-125.

16. Haskó G, Pacher P (2008) A2A receptors in inflammation and injury: lessons 
learned from transgenic animals. J Leukoc Biol 83: 447-455.

17. Morello S, Sorrentino R, Pinto A (2009) Adenosine A2a receptor agonists as regulators of inflammation: pharmacology and therapeutic opportunities. J Receptor Ligand 2: 11-17.

18. Impellizzeri D, Di Paola R, Esposito E, Mazzon E, Paterniti I, et al. (2011) CGS 21680, an agonist of the adenosine (A2A) receptor, decreases acute lung inflammation. Eur J Pharmacol 668: 305-316.

19. Ren T, Qiu Y, Wu W, Feng X, Ye S, et al. (2014) Activation of adenosine A3 receptor alleviates TNF- -induced inflammation through inhibition of the NF- B signaling pathway in human colonic epithelial cells. Mediators Inflamm: 818251 .

20. Baharav E, Bar-Yehuda S, Madi L, Silberman D, Rath-Wolfson L, et al. (2005) Antiinflammatory effect of A3 adenosine receptor agonists in murine autoimmune arthritis models. J Rheumatol 32: 469-476.

21. Vincenzi F, Padovan M, Targa M, Corciulo C, Giacuzzo S, et al. (2013) $\mathrm{A}(2 \mathrm{~A})$ adenosine receptors are differentially modulated by pharmacological treatments in rheumatoid arthritis patients and their stimulation ameliorates adjuvant-induced arthritis in rats. PLoS One 8: e54195

22. Reiss AB, Cronstein BN (2012) Regulation of foam cells by adenosine. Arterioscler Thromb Vasc Biol 32: 879-886.

23. Bingham TC, Fisher EA, Parathath S, Reiss AB, Chan ES, et al. (2010) A2A adenosine receptor stimulation decreases foam cell formation by enhancing ABCA1-dependent cholesterol efflux. J Leukoc Biol 87: 683-690.

24. Koupenova M, Johnston-Cox H, Ravid K (2012) Regulation of atherosclerosis and associated risk factors by adenosine and adenosine receptors. Curr Atheroscler Rep 14: 460-468.

25. Voloshyna I, Carsons S, Littlefield MJ, Rieger JM, Figler R, et al. (2013) Adenosine $\mathrm{A}(2 \mathrm{~A})$ receptor activation supports an atheroprotective cholestero balance in human macrophages and endothelial cells. Biochim Biophys Acta 1831: $407-416$

26. Qin $Z$ (2012) The use of THP-1 cells as a model for mimicking the function and regulation of monocytes and macrophages in the vasculature. Atherosclerosis 221: 2-11.

27. Reiss AB, Wan DW, Anwar K, Merrill JT, Wirkowski PA, et al. (2009) Enhanced CD36 scavenger receptor expression in THP-1 human monocytes in the presence of lupus plasma: linking autoimmunity and atherosclerosis. Exp Biol Med (Maywood) 234: 354-360.

28. Ferrante CJ, Leibovich SJ (2012) Regulation of Macrophage Polarization and Wound Healing. Adv Wound Care (New Rochelle) 1: 10-16.

29. Shin S, Moon S, Park Y, Kwon J, Lee S, et al. (2009) Role of Cordycepin and Adenosine on the Phenotypic Switch of Macrophages via Induced Antiinflammatory Cytokines. Immune Netw 9: 255-264.

30. Martinez FO, Helming L, Milde R, Varin A, Melgert BN, et al. (2013) Genetic programs expressed in resting and IL-4 alternatively activated mouse and human macrophages: similarities and differences. Blood 121: e57-69.
31. Murray PJ, Allen JE, Biswas SK, Fisher EA, Gilroy DW, et al. (2014) Macrophage activation and polarization: nomenclature and experimental guidelines. Immunity 41: 14-20.

32. Engström A, Erlandsson A, Delbro D, Wijkander J (2014) Conditioned media from macrophages of $M 1$, but not $M 2$ phenotype, inhibit the proliferation of the colon cancer cell lines HT-29 and CACO-2. Int J Oncol 44: 385-392.

33. Jager N, Teteloshvili N, Zeebregts C, Westra J, Bijl M (2012) Macrophage folate receptor- $\beta$ (FR- $ß$ ) expression in auto-immune inflammatory rheumatic diseases: A forthcoming marker for cardiovascular risk? Autoimmun Rev 11: 621-626.

34. Waldo SW, Li Y, Buono C, Zhao B, Billings EM, et al. (2008) Heterogeneity of human macrophages in culture and in atherosclerotic plaques. Am J Pathol 172: $1112-1126$

35. Stöger JL, Gijbels MJ, van der Velden S, Manca M, van der Loos CM, et al. (2012) Distribution of macrophage polarization markers in human atherosclerosis. Atherosclerosis 225: 461-468.

36. Moore KJ, Sheedy FJ, Fisher EA (2013) Macrophages in atherosclerosis: a dynamic balance. Nat Rev Immunol 13: 709-721.

37. Colin S, Chinetti-Gbaguidi G, Staels B (2014) Macrophage phenotypes in atherosclerosis. Immunol Rev 262: 153-166.

38. Bouhlel MA, Derudas B, Rigamonti E, Dièvart R, Brozek J, et al. (2007) PPARgamma activation primes human monocytes into alternative M2 macrophages with anti-inflammatory properties. Cell Metab 6: 137-143.

39. Reiss AB, Awadallah NW, Cronstein BN (2000) Cytochrome P450 cholesterol 27-hydroxylase: an anti-atherogenic enzyme. Recent Research Devel in Lipids Res 4: 39-50.

40. Canton J, Neculai D, Grinstein S (2013) Scavenger receptors in homeostasis and immunity. Nat Rev Immunol 13: 621-634.

41. Lehrke M, Millington SC, Lefterova M, Cumaranatunge RG, Szapary $P$, et al. (2007) CXCL16 is a marker of inflammation, atherosclerosis, and acute coronary syndromes in humans. J Am Coll Cardiol 49: 442-449.

42. Raes G, Van den Bergh R, De Baetselier P, Ghassabeh GH, Scotton C et al. (2005) Arginase-1 and $Y m 1$ are markers for murine, but not human alternatively activated myeloid cells. J Immunol 174: 6561.

43. Everett BM, Pradhan AD, Solomon DH, Paynter N, Macfadyen J, et al. (2013) Rationale and design of the Cardiovascular Inflammation Reduction Trial: a test of the inflammatory hypothesis of atherothrombosis. Am Heart J 166: 199-207.

44. Coomes E, Chan ES, Reiss AB (2011) Methotrexate in atherogenesis and cholesterol metabolism. Cholesterol 2011: 503028.

45. Voloshyna I, Hai O, Littlefield MJ, Carsons S, Reiss AB (2013) Resveratrol mediates anti-atherogenic effects on cholesterol flux in human macrophages and endothelium via PPAR ${ }^{3}$ and adenosine. Eur J Pharmacol 698: 299-309.

46. Ferrante CJ, Pinhal-Enfield G, Elson G, Cronstein BN, Hasko G, et al. (2013) The adenosine-dependent angiogenic switch of macrophages to an M2-like phenotype is independent of interleukin-4 receptor alpha (IL-4Ra) signaling. Inflammation 36: 921-931. 